\title{
Ricardo Flórez Gaviño y su contribución al avance tecnológico de la medicina
} peruana

\author{
Ricardo Flórez Gaviño and his contribution to \\ the technological advancement of Peruvian \\ medicine
}

Ricardo Iván Álvarez-Carrasco '
Álvarez-Carrasco RI. Ricardo Flórez Gaviño y su contribución al avance tecnológico de la medicina peruana. 2021;34(2): 82-85. https://doi.org/10.36393/spmi.v34i2.602

\begin{abstract}
RESUMEN
El doctor Ricardo Flórez Gaviño es sin lugar a dudas uno de los principales contribuyentes en el avance tecnológico de la medicina peruana y de otros campos de la actividad humana, en el período comprendido entre los últimos lustros del siglo XIX y los primeros de la centuria siguiente; sin embargo, su vida y obra son desconocidos para la gran mayoría de los peruanos, en particular para los miembros de la orden médica nacional. El propósito de este artículo es dar a conocer y revalorizar la fascinante existencia y la proficua labor de este médico limeño.
\end{abstract}

Palabras claves: historia, medicina peruana, microscopía, microbiología, oftalmología.

\section{ABSTRACT}

Dr. Ricardo Flórez Gaviño is undoubtedly one of the main contributors to the technological advance of Peruvian medicine and other fields of human activity, in the period between the last five years of the 19th century and the first of the following century. However, his life and work are unknown to the vast majority of Peruvians, particularly to members of the national medical order. The purpose of this article is to publicize and revalue the fascinating existence and profitable work of this Lima doctor.

Keywords: History, Peruvian medicine, microscopy, microbiology, ophtalmology

Médico patólogo clínico. Instituto Nacional Materno Perinatal. Asociación de Historia de la Medicina Peruana y Parques Conmemorativos, Lima, Perú.

\section{INTRODUCCIÓN}

Los médicos peruanos que vivieron y ejercieron luego de la Guerra del Pacífico (1879-1883), en general, tuvieron el afán de incorporar las nacientes tecnologías que estaban revolucionando la práctica de la profesión por aquellos años, las cuales se descubrían y desarrollaban, en su gran mayoría, en los principales países de Europa y los Estados Unidos de América. En ese contexto destacó nítidamente el doctor Ricardo Flórez Gaviño quien no sólo introdujo aquellas relacionadas con la medicina, sino también otros referidas a la fotografía, cinematografía y automovilismo.

\section{SUS PRIMEROS AÑOS DE VIDA}

Nuestro personaje nació en la ciudad de Lima, el jueves 10 de agosto de 1854, ${ }^{1}$ era hijo de Sebastián Flórez y Pascuala Gaviño, ${ }^{2}$ quienes lo bautizaron con los nombres Ricardo Lorenzo (Figura 1). Tiempo después, la familia se trasladó al cercano puerto del Callao, donde hizo sus primeras letras en la escuela que dirigían los señores Alegría y Vargas. ${ }^{3}$

Cuando apenas frisaba los once años, ingresó al Instituto Militar, una entidad más o menos equivalente a la actual 


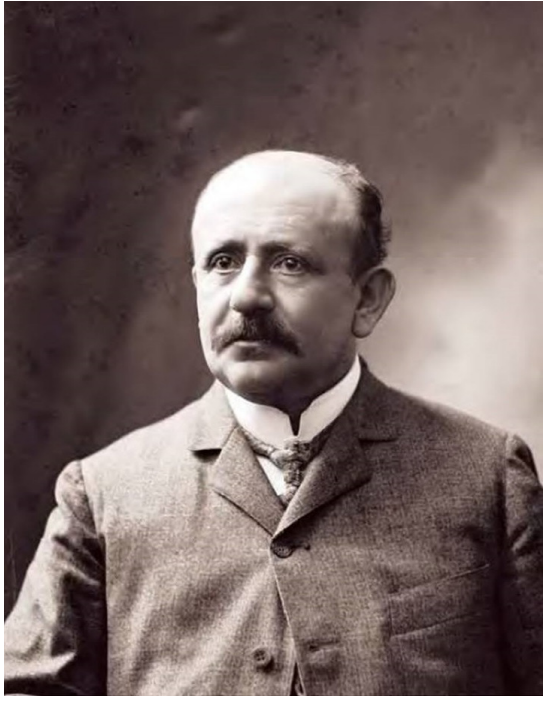

Figura I. Doctor Ricardo Lorenzo Flórez Gaviño. Ministro de Justicia, Culto e Instrucción. Año I9/8. Fotógrafo no identificado.

Escuela Militar de Chorrillos, que por entonces aceptaba cadetes desde esa tierna edad; y, en tal condición participó en el combate del Callao, el 2 de mayo de 1866, sentando plaza en la batería El Sol de Ayacucho. ${ }^{3}$ Algunas fuentes refieren que estuvo bajo las órdenes del entonces comandante Francisco Bolognesi, pero aquel militar no participó en esa contienda ya que se hallaba en Guayaquil, en su camino de retorno al Perú; y, lo realmente cierto es que los cañones Blakely que adquirió en Europa se utilizaron aquel día. ${ }^{4}$ En 1867 participó, integrando el batallón Yungay $\mathrm{N}^{\circ}$ 6, que era leal al presidente Mariano Ignacio Prado, en las acciones contra los insurrectos en el sur del país. ${ }^{3}$ Resultó herido en la mandíbula, por lo que regresó a Lima para ser curado y luego de recuperarse abandonó para siempre la vida militar.

\section{ESTUDIOS MÉDICOS}

En 1871 ingresó a la Facultad de Medicina de San Fernando, ${ }^{5}$ pero aún siendo estudiante viajó a Francia, reiniciando dicha carrera en la Universidad de París, también conocida como La Sorbona. Allí la cursó exitosamente y consolidó su dominio del idioma galo, al punto que obtuvo, por concurso público, una plaza de interno en el afamado hospital Hotel-Dieu de aquella ciudad, y en 1878 obtuvo el título de médico cirujano y el grado de doctor con la tesis Los tumores estercoráceos. ${ }^{1}$

\section{SU PARTICIPACIÓN COMO CIRUJANO EN LA DEFENSA DE LIMA}

Hallándose aún en tierras francesas, tomó conocimiento del inicio de la Guerra del Pacífico, por lo que apenas le fue posible emprendió el regreso al Perú, con las dificultades y peligros que ello implicaba, arribando en el trascurso de 1880, lo que le permitió participar durante la defensa de Lima, en las batallas de San Juan y Miraflores, el 13 y 15 de enero de 1881, respectivamente, como cirujano mayor y jefe de una de las ambulancias volantes del Ejército de Reserva. $^{6}$

\section{NUESTRO PRIMER MICROSCOPIO ÓPTICO BINOCULAR Y LA ENSEÑANZA DE LA MICROSCOPÍA EN EL PERÚ}

Luego de la guerra, regresó a París con el fin de hacer estudios de posgrado, especializándose en la técnica microscópica. ${ }^{7}$ Al retornar trajo consigo el primer microscopio óptico monocular que hubo entre nosotros, con el que, a principios de octubre de 1885, realizó el primer recuento de glóbulos rojos, de nuestros anales médicos, a un estudiante que, pocos días después, se elevó a la gloria y cuyo nombre fue Daniel Alcides Carrión. ${ }^{8}$ Los resultados de aquel recuento revelaban que el paciente padecía de una anemia aguda y severa, por lo que prescribió su traslado a la Maisón de Santé, donde laboraba Flórez, con vistas a practicarle una

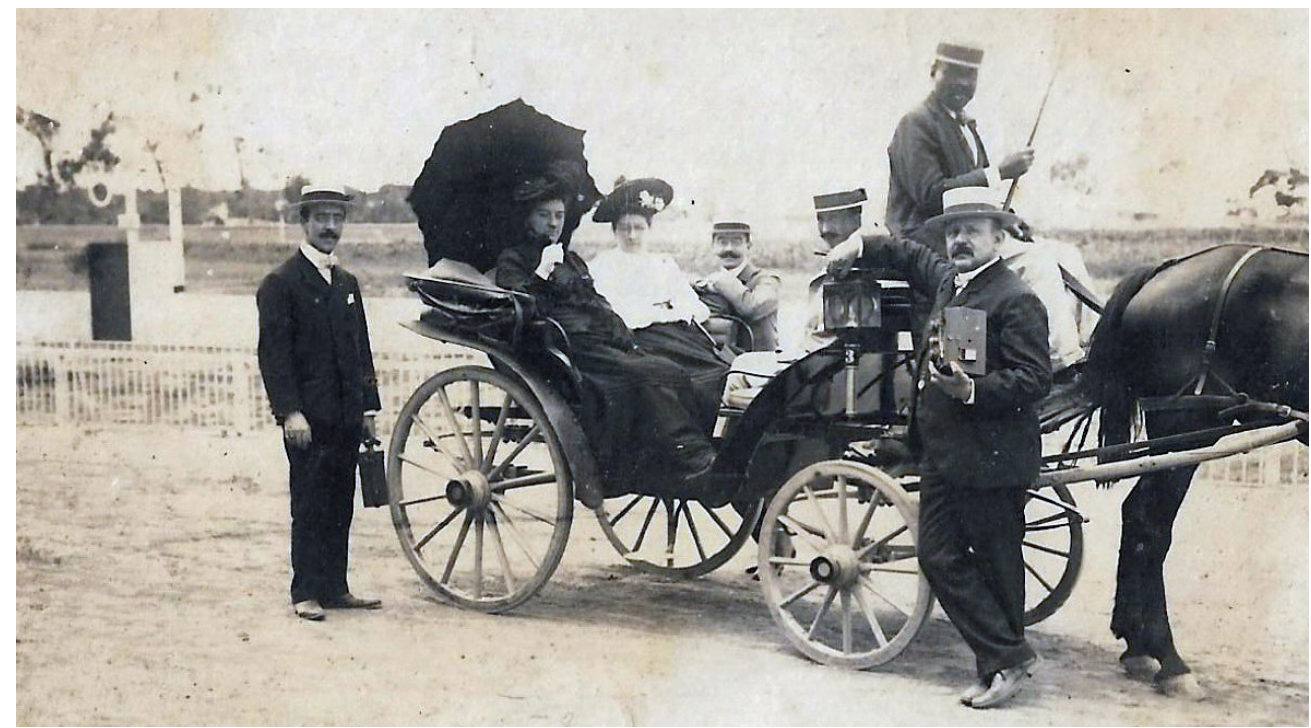

Figura 2. Doctor Flórez con una cámara fotográfica en las manos, acompañado por su esposa y un grupo de amigos. Hipódromo de Santa Beatriz. Década de 1910. 
transfusión de sangre que, finalmente, no se realizó, y que tal vez le hubiera salvado la vida. ${ }^{8}$

En los primeros meses de 1889, nuestro biografiado ofreció a las autoridades de la Facultad de Medicina San Fernando, sus servicios docentes, el microscopio de su propiedad y otros implementos, con el propósito de dictar, a título gratuito, los cursos que requirieran de este novedoso aparato. ${ }^{8}$ El 20 de mayo de aquel año, el decano Leonardo Villar Naveda le comunicaba que su petición había sido aprobada. ${ }^{8}$

A mediados de 1889, inició el dictado teórico y práctico del curso de técnica microscópica, que concluyó el 27 de noviembre, y solo pidió que las autoridades sanfernandinas le entregaran un certificado que atestiguara su desinteresada colaboración. $^{8}$ Ese mismo año había publicado una investigación pionera en nuestra microbiología, la cual tituló Estudio bacteriológico del aire y de las aguas de Lima y sus alrededores. ${ }^{9}$

El 16 de junio de 1890, el gobierno promulgó la ley que creaba la cátedra de bacteriología y técnica microscópica, ${ }^{10}$ designando como su profesor fundador al médico cusqueño David Matto Usandivaras. ${ }^{11}$ El doctor Flórez, que era un notorio partidario de Nicolás de Piérola, enemigo acérrimo de aquel mandatario, sería desplazado de la cátedra por evidentes razones políticas, además Matto era un antiguo miembro del partido Constitucional, que lideraba Cáceres. ${ }^{8}$

\section{LA CÁTEDRA DE OFTALMOLOGÍA Y EL RESTO DE SU LABOR EN SAN FERNANDO}

El 29 de julio de 1895 se le designó como catedrático interino de oftalmología en San Fernando, ${ }^{5}$ y el 9 de mayo de 1896 obtuvo su titularidad, al ganar el concurso donde tuvo como opositor al doctor Eduardo Gaffron, médico suizo avecindado en Lima; Flórez ejerció la cátedra hasta $1911.3,6$

El 16 de marzo de 1921, cuando Flórez ocupaba la plaza de subdecano de San Fernando, el doctor Ernesto Odriozola Benavides, entonces decano de dicha corporación, falleció abruptamente, por lo que debió reemplazarlo; ${ }^{12}$ sin embargo, apenas en mayo de aquel año, el gobierno de Augusto B. Leguía decidió recesar y reorganizar la universidad. ${ }^{13}$ En tal circunstancia no dudó en firmar el manifiesto que redactaron los profesores de San Marcos en defensa de las libertades públicas. ${ }^{8}$

\section{LA PARTICIPACIÓN EN LA POLÍTICA}

En 1884 estuvo entre los fundadores del Partido Demócrata liderado por Nicolás de Piérola, cuyo comité ejecutivo integró en varias ocasiones; esta militancia le costó los destierros a Guayaquil, entre 1890 y 1891, e Iquique, entre 1894 y 1895; y, no obstante, en ambos lugares ejerció la profesión médica y se granjeó una numerosa clientela particular. $^{1}$

En 1895, después del triunfo de la revolución de Piérola fue elegido senador por el Callao, que desempeñó hasta 1896; luego, ocupó el ministerio de Fomento, entre el 27 de noviembre de 1897 y el 16 de mayo de $1898 .{ }^{1}$

En este último cargo, gestionó ante dicho mandatario, que era su antiguo amigo y compañero de correrías políticas, la autorización y el prepuesto para la construcción del nuevo local de San Fernando, en la alameda Grau, ${ }^{6}$ cuyos trabajos se iniciarían el 3 de setiembre de $1899,{ }^{14}$ apenas cinco días antes que Piérola entregara el mando a su sucesor, Eduardo López de Romaña.

En 1902, las insalvables diferencias políticas con Piérola lo llevaron a renunciar al Partido Demócrata, y luego figuró entre los fundadores del Partido Liberal, liderado por el político y empresario huanuqueño Augusto Durand Maldonado. ${ }^{1}$ En esta nueva organización, ocupó el cargo de vicepresidente y fue electo senador por Huánuco de 1907 a 1909 y de 1910 a 1918 ; $^{2,12}$ siendo vicepresidente de esa cámara en $1916 .{ }^{\circ}$

Durante el segundo gobierno de José Pardo Barreda, desempeñó las funciones de ministro de Justicia, Culto e Instrucción, entre el 27 de julio de 1917 y el 26 de noviembre de 1918, y fugazmente la cartera de Relaciones Exteriores, entre el 6 al 18 de diciembre de $1918 .^{8}$

\section{SU CONTRIBUCIÓN A LOS AVANCES TECNOLÓGICOS EN LA MEDICINA Y MÁS ALLÁ DE ELLA}

Nuestro personaje fue sin duda uno de los principales introductores y promotores de nuevas tecnologías en el país, además de traer el primer microscopio óptico monocular hizo lo propio con el termómetro de uso médico, las jeringas hipodérmicas, y los medios de cultivo sólidos. ${ }^{8}$ No conforme con ello, el 14 de julio de 1888, coincidiendo con el aniversario patrio de Francia, estuvo entre los fundadores y fue el primer presidente del Foto Club de Lima, la primera entidad nacional que agrupó a los cultores de este pasatiempo (Figura 2); lo acompañó el doctor Matto como integrante de su junta directiva. ${ }^{15}$

En 1903 importó el primer automóvil que circuló en Lima, un vehículo de la marca norteamericana Locomobile, y que se animó a conducir la mañana del 2 de noviembre, ${ }^{1}$ saliendo de su residencia de la calle Mariquitas -hoy tercera cuadra del jirón Moquegua de Lima-, hacia al Paseo Colón, la Alameda de los Descalzos y la calle Palacio con dirección a la Plazoleta de Desamparados. En esa circunstancia, al no saber cómo apagar el automóvil, vio venir dos tranvías a caballo y para evitar la inminente colisión tiró fuertemente de la palanca, logrando detenerlo, pero la pendiente de la calle hizo que retrocediera hasta estrellarse contra una pastelería. ${ }^{16} \mathrm{Al}$ año siguiente importó un segundo automóvil esta vez de la marca francesa Richard Brasier, a gasolina, de cuatro cilindros, sin bujías y con cuatro asientos. ${ }^{1}$

El 24 de agosto de 1908, estuvo entre los accionistas que fundaron la Empresa del Cinema Teatro, la cual construyó la primera sala permanente de exhibiciones cinematográficas que hubo en el Perú, en la calle Belén, hoy décima cuadra del jirón de la Unión, en el Cercado de Lima. ${ }^{17}$ Esta compañía, en noviembre de 1913, contrató a Jorge Goytisolo para la filmación del Quinto Congreso Médico Latinoamericano y el Sexto Congreso Panamericano de Medicina, ambos desarrollados simultáneamente en Lima. Así, se filmó la ceremonia inaugural llevada a cabo en el teatro Municipal, 
las visitas de los asambleístas a la Facultad de Medicina de San Fernando y el Hospital Dos de Mayo, y la excursión a la estación sanitaria de la isla San Lorenzo. ${ }^{17}$ Ello constituyó otro hito tecnológico en el que se involucró el doctor Flórez, siendo el primer evento médico filmado en la historia del Perú.

\section{OTROS CARGOS, ENCARGOS Y DISTINCIONES}

El 3 de enero de 1896, el régimen del presidente Nicolás de Piérola promulgó la ley que encargaba al doctor Flórez la formulación del proyecto de creación del Instituto Nacional de Vacuna, tal como cumplió en los plazos que se le fijaron. ${ }^{18}$ Gracias a ello, el 22 de mayo de 1896, se emitió el Decreto Supremo que creaba el Instituto de Vacuna, ${ }^{19}$ que cuarenta años después, en 1936, se convertiría en el Instituto Nacional de Higiene y Salud Pública, actualmente denominado Instituto Nacional de Salud.

Estuvo entre los fundadores de la Academia Nacional de Medicina (ANM), ${ }^{20}$ que presidió entre 1913 a $1918,{ }^{12}$ y formó parte del comité de redacción del Monitor Médico, una publicación periódica que se editaba con el auspicio de la ANM. También presidió la Sociedad Geográfica de Lima, entre 1898 y $1899 .^{2}$

Estuvo muy ligado a la comunidad francesa de nuestro país, laborando por sesenta años en la Clínica Maison de Santé de Lima, también conocido como el Hospital Francés, ocupando su dirección por cincuenta y siete años, y en esa condición atender al pequeño José Carlos Mariátegui, de apenas ocho años de edad, quien había sido internado en aquel establecimiento, en 1902, para restablecerse de una afección de su rodilla izquierda, y donde el futuro Amauta tuvo su primer contacto con el idioma francés.

Flórez también ejerció como médico de la legación francesa en el Perú y ocupó el cargo de presidente del Comité Franco Peruano, que ejerció hasta su fallecimiento. ${ }^{20}$ En virtud de ello, en 1901, el gobierno de la República Francesa le concedió la condecoración de la Legión de Honor, en reconocimiento a los generosos servicios que prestó a la colonia gala en el Perú. ${ }^{5}$

\section{EL TERMINO DE SU VIDA TERRENAL}

Estando enfermo de gripe, no dudó en hacer una consulta domiciliaria a uno de sus pacientes, que dio como resultado una grave complicación pulmonar que lo llevó a la muerte, en su ciudad natal, el miércoles 15 de noviembre de 1939. ${ }^{20}$ En su sepelio estuvo presente la comunidad médica en pleno y el doctor Carlos Enrique Paz Soldán, secretario perpetuo de la ANM, sintetizaba su vida en la siguiente expresión: "Yace aquí un médico que habiendo conocido los honores, las luchas y las amarguras de la existencia, jamás conoció el odio". ${ }^{12}$

El doctor Flórez había contraído matrimonio con María del Carmen Gutiérrez de Quintanilla Flores, con la que tuvo un hijo homónimo, que sería un pintor paisajista y maestro en la Escuela Nacional de Bellas Artes.

\section{COLOFÓN}

El espacio limitado de un artículo no permite desarrollar en su integridad la vida multifacética y llena de acontecimientos trascendentes como la del doctor Flórez, simplemente se ha pretendido narrar los hechos más saltantes para que su memoria no se pierda irremediablemente bajo el espeso velo del trascurrir del tiempo.

\section{REFERENCIAS BIBLIOGRÁFICAS}

I. Lara E. Historia del Ministerio de Fomento y Obras Públicas. Tomo I. Lima: Imprenta y Librería del Gabinete Militar; 1935. p. I22-I3I.

2. Belmont W. Peruvians of to day. The Hispanic Society of America. Lima: Southwell Press; 1919. p.92-94,494,495.

3. Paz-Soldán J. Diccionario Biográfico de Peruanos Contemporáneos. Lima: Librería e Imprenta Gil; I917. p.227.

4. Neira H. Francisco Bolognesi. En:Alva Orlandini H (edit.). Biblioteca Hombres del Perú. Lima: Pontificia Universidad Católica del Perú; 2003. p.566.

5. Valdizán H. Diccionario de Medicina Peruana. Tomo IV. Parte II. An Fac Med. 1958; (Supl.): I 21, I 22, I5I, 152.

6. Arias-Schreiber J, Zanutelli M. Médicos y farmacéuticos en la Guerra del Pacífico. Lima: Editorial e Imprenta DESA; I984. p. I29, I30.

7. Rabí M. Diccionario Histórico Biográfico Médico del Perú. Lima: Larchgrafic SAC; 2007. p.250,25I.

8. Álvarez C. Los primeros 100 años de la Patología Clínica en el Perú 1856-1958. Lima: Asociación Médica Peruana de Patología Clínica; 202I. p.62-68, I33.

9. Flórez R. Estudio bacteriológico del aire y las aguas de Lima y sus alrededores. La Crónica Médica Lima. I889;6(68):I79-81.

10. Matto D. La enseñanza médica en el Perú. Lima:Tipografía El Lucero; 1908. p.31,42.

II. Lastres J. Historia de la medicina peruana. Volumen III. Universidad Nacional Mayor de San Marcos. Lima: Imprenta Santa María; I95I. p. $25 \mathrm{I}, 276,286,287,324$

12. Avendaño J. Perfiles de la medicina peruana. Lima: Imprenta de la UNMSM; 1983. p.13,14.

13. Guadalupe M. La universidad como campo de batalla: el receso de la Universidad de San Marcos, 1921-1922. En Líneas Generales. 2018; I (2): I31-42.

14. Iniciación de los trabajos de la nueva Escuela de Medicina. La Crónica Médica Lima. 1899; 16(257):317.

15. Gargurevich J. Del grabado a la fotografía. Las ilustraciones en el periodismo peruano. San Marcos. 2006;24:133-50.

16. Crónica. La primera vez que circuló un auto en Lima. El Comercio $\mathrm{N}^{\circ}$ 90040, Año 178. Lima, 28 Abr 20I8. p. 14

17. Bedoya R. El cine silente en el Perú. Primera reimpresión. Lima: Departamento de impresiones de la Universidad de Lima; 2013. p.67,68, 126

18. Ballesteros A. La vacuna y su profilaxis. Lima: Imprenta El Boletín de Ciencias, Artes e Industrias; 1919. p. 23,78-91.

19. Instituto Nacional de Vacuna. Creación e instalación. Lima llustrado. 1900;2(46): 894-5.

20. Necrología. Dr. Ricardo L. Flórez. La Crónica Médica Lima. 1939;56:357-8.

CORRESPONDENCIA:

Ricardo Iván Álvarez-Carrasco

ralvarezcarrasco@yahoo.com

ORCID 0000-0002-0987-67I7, Scopus Author ID 57I94734963

Fecha de recepción: 09-05-2021.

Fecha de aceptación: 06-06-202I.

Financiamiento: por el autor.

Conflicto de interés: ninguno, según el autor. 